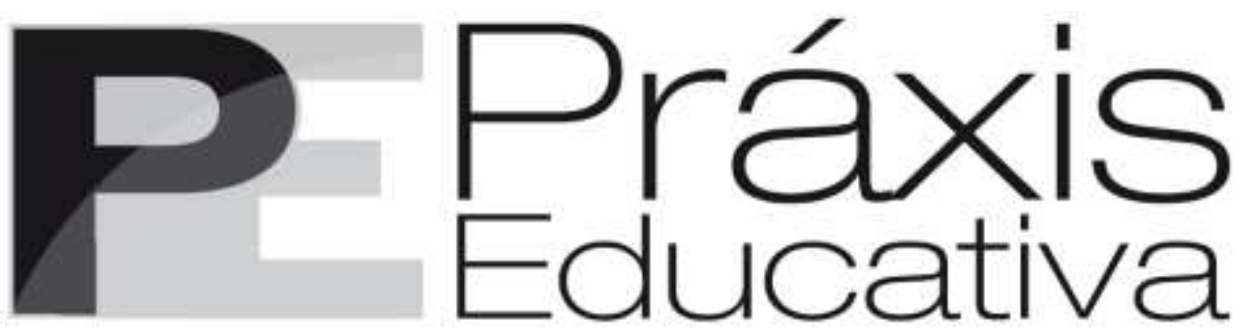

ISSN 1809-4031

eISSN 1809-4309

https://doi.org/10.5212/PraxEduc.v.17.19374.002

Dossiê: Relacõos étnico-raciais: práticas e reflexões pedagógicas em contextos, espaços e tempos

\title{
Mulheres negras em movimento: criações individuais e coletivas por vidas com dignidade e direitos
}

\author{
Black women on the move: individual and collective creations \\ for lives with dignity and rights
}

\section{Mujeres negras en movimiento: creaciones individuales y colectivas para vidas con dignidad y derechos}

Matilde Ribeiro*
(D) https://orcid.org/0000-0002-5161-5924

Resumo: Este artigo contém três eixos: a determinação pela vida digna; 33 anos de organização nacional e internacional; e a criatividade a serviço da construção acadêmica do conhecimento. A organização é histórica, e, na busca de ampliação da plataforma feminista, antirracista e anti-homofóbica, as mulheres negras teceram inúmeras críticas quanto à invisibilidade de sua ação política nos movimentos sociais (em especial o negro e o feminista) e na sociedade. A contestação mais direta refere-se à maneira secundarizada no tratamento de sua opressão e organização. Desse modo, seja por meio dos discursos políticos, dos comportamentos e/ou da produção teórica, as mulheres negras apareceram historicamente como sujeitos implicitos. No período contemporâneo, motivadas pela busca de superação do racismo, sexismo, LGBTfobia e desigualdades sociais, econômicas e sociais, as mulheres negras têm tido êxito em seu processo organizativo com o ativismo político, social e acadêmico.

Palavras-chave: Mulheres negras em movimento. Organização de mulheres negras. Racismo, sexismo e LGBTfobia.

Abstract: This article contains three axes: the determination for a dignified life; 33 years of national and international organization; and creativity in the service of the academic construction of knowledge. Such an organization is historic, and, in the search for broadening the feminist, anti-racist and anti-homophobic platform, black women made numerous criticisms regarding the invisibility of their political action in social movements (especially the black and feminist ones) and in society. The most direct challenge refers to the secondary way of treating their oppression and organization. Thus, whether through political discourses,

\footnotetext{
${ }^{*}$ Doutora em Serviço Social. Recebeu, em 2021, pela Fundação Universidade Federal do ABC (UFABC), o título de Doutora Honoris Causa. É professora adjunta na Universidade da Integração Internacional da Lusofonia AfroBrasileira (Unilab) no Instituto de Humanidades/Curso de Pedagogia no Campus Liberdade/Redenção, Ceará. E-mail: <mribeiro@unilab.edu.br>.
} 
behaviors and/or theoretical production, black women have historically appeared as implicit subjects. Up to date, motivated by the search to overcome racism, sexism, LGBTphobia and social, economic and social inequalities, black women have been successful in their organizational process with political, social and academic activism.

Keywords: Black women on the move. Organization of black women. Racism, sexism and LGBTphobia.

Resumen: Este artículo contiene tres ejes: la determinación por una vida digna; 33 años de organización nacional e internacional; y la creatividad al servicio de la construcción académica del conocimiento. La organización es histórica y, en la búsqueda de ampliar la plataforma feminista, antirracista y antihomofóbica, las mujeres negras realizaron numerosas críticas sobre la invisibilidad de su acción política en los movimientos sociales (especialmente el negro y el feminista) y en la sociedad. El desafío más directo se refiere a la manera secundarizada en lo que se trata de su opresión y organización. De ese modo, ya sea por medio de discursos políticos, de los comportamientos y/o de la producción teórica, las mujeres negras han aparecido históricamente como sujetos implícitos. En la época contemporánea, motivadas por la búsqueda de superación del racismo, el sexismo, la LGBTfobia y desigualdades sociales, económicas y sociales, las mujeres negras han tenido éxito en su proceso organizativo, con el activismo político, social y académico.

Palabras clave: Mujeres negras en movimiento. Organización de mujeres negras. Racismo, sexismo y LGBTfobia.

\section{Introdução}

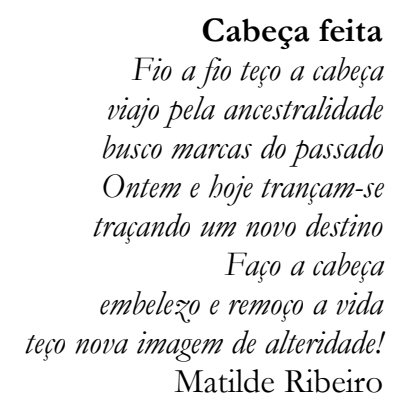

Trançando e traçando novos destinos, o poema Cabeça feita significa um profundo respiro pela vida, aponta para a busca de lugar de alteridade. O poema encaixa-se no que Conceição Evaristo $^{1}$ define como Escrevivência. Em entrevista para a Revista Nexo (LIMA, 2017, n.p.), Conceição Evaristo informa que "[...] as nossas escrevivências contam as nossas histórias a partir das nossas perspectivas, é uma escrita que se dá colada à nossa vivência, seja particular ou coletiva, justamente para acordar os da Casa Grande".

O poema Cabeça Feita, de minha autoria, foi escrito em janeiro de 1993. Após 28 anos, representa o traçado de reflexões que serão desenvolvidas neste artigo. A elaboração deste texto partiu de revisitação ao Mestrado e ao Doutorado $^{2}$, que trataram das questões de classe social, gênero, raça e políticas públicas, a partir de pesquisas qualitativas. Especificamente, o artigo afirma conhecimento empírico, partindo de experiências do ativismo político, como educadora em organizações não governamentais, como gestora pública e como docente de nível superior.

\footnotetext{
${ }^{1}$ Escritora nascida em Belo Horizonte, Minas Gerais, em 29 de novembro de 1946. É oriunda de família pobre, segunda de nove irmãos, sendo a primeira a conseguir um diploma universitário. É uma grande expoente da literatura contemporânea, romancista, poeta e contista, homenageada como Personalidade Literária do Ano pelo Prêmio Jabuti (2019) e vencedora do Prêmio Jabuti (2015).

2 O Mestrado e o Doutorado foram realizados na Pontifícia Universidade Católica de São Paulo (PUC/SP). A dissertação foi defendida em 1999 e teve como título Gênero e raça no processo do orçamento participativo: Santo André, 19971998. A tese foi defendida em 2013 e teve como título Institucionalização das Politicas de Promoção da Igualdade Racial no Brasil: percursos e estratégias - 1986 A 2010.
}

Práxis Educativa, Ponta Grossa, v. 17, e2219374, p. 1-18, 2022 Disponível em: < https:// revistas2.uepg.br/index.php/praxiseducativa $>$. 
A principal referência deste artigo é a discussão sobre os modos de vida e de resistência das mulheres negras, sob a perspectiva do feminismo negro. Assim foi realizada pesquisa bibliográfica para impulsionar reflexões teórico-políticas sobre racismo, sexismo, LGBTfobia, mulheres negras em movimento, destacar a indissociabilidade entre classe social, raça e gênero e enfocar a importância da luta das feministas negras como negação e enfrentamento cotidiano à secundarização das pautas reivindicatórias, de invisibilidade, de exploração, de opressão e de violências sexuais-identitárias-étnico-raciais. Diante desse contexto, este texto possui três seções que se referem à vida das mulheres negras: a determinação pela vida digna; o processo de organização nacional e internacional no período contemporâneo; e a criatividade a serviço da construção acadêmica do conhecimento.

\section{Mulheres negras no cotidiano: a determinação pela vida digna}

Em um primeiro momento, apresentarei a instigante história de Maria do Carmo Gerônimo, nascida em Carmo de Minas, em 5 de março de 1871, com falecimento em Itajubá, em 14 de junho de 2000. Segundo a Wikipédia (2020, n.p.), “[...] foi uma ex-escrava brasileira que teria sido uma das pessoas mais velhas do mundo que se tem registro". Contudo, por falta de qualquer documento civil, ela não pôde ser incluída no livro Guinness Book (Livro dos recordes). Maria do Carmo morreu com 129 anos, deixou de ser escrava apenas com a Abolição da Escravidão em 1888, quando tinha 17 anos, considerando que a Lei do Ventre Livre só foi sancionada no dia 28 de setembro de 1871, meses após o seu nascimento.

Conheci Maria do Carmo Gerônimo, na Câmara de Vereadores de São Paulo, no dia 30 de maio de 1994, quando recebeu o título de Cidadã Paulistana. Minha curiosidade com a vida dessa mulher negra foi tamanha, que três meses depois fui visitá-la, em Itajubá, Minas Gerais. De minha visita, resultou uma entrevista que, junto a outras fontes bibliográficas, gerou o artigo, em 1996, denominado Todas Negras: uma vida, muitas vidas (RIBEIRO, 1996).

Em 1994, ocorreu um fato escandaloso envolvendo a vida de Maria do Carmo. Setores do Movimento Negro de Minas Gerais apresentaram à Câmara de Vereadores de Itajubá um projeto que concederia a ela o título de Cidadã Itajubense, mas a iniciativa foi vetada. Segundo avaliação das vereadoras e dos vereadores, provavelmente provenientes ou com ideário da elite branca, não havia porque conceder um título a uma ex-escrava. Tal negativa virou notícia na imprensa local e nacional, motivada por enorme indignação e lamento com a hipocrisia da "tão decantada democracia racial no Brasil" (Jornal do Sul de Minas, 30 de abril de 1994).

Em um ato de desagravo pelo veto feito pela Câmara de Vereadores de Itajubá, a Câmara de Vereadores de São Paulo, no dia 30 de maio de 1994, por iniciativa do vereador Vital Nolasco (Partido Comunista do Brasil - PCdoB), concedeu à Maria do Carmo o título de Cidadã Paulistana. O evento foi um marco político, com todas as honrarias, homenagens e a presença de autoridades, imprensa e militantes do Movimento Negro de São Paulo.

$\mathrm{Na}$ entrevista que realizei com Maria do Carmo em 1994, obtive poucos relatos pessoais ou de sua vivência no período da escravidão, mas foi possível perceber que os efeitos dos maus tratos ficaram em seu corpo, pois verifiquei marcas de queimaduras em suas costas e braços. No diálogo, captei algumas importantes questões: não viveu para si, guardava lembranças do trabalho como empregada doméstica, não constituiu família e tinha uma forte ligação com o catolicismo. Ficou evidente que o motor de sua vida foi o trabalho como empregada doméstica - o último foi iniciado quando tinha 75 anos, absurdamente na idade em que já deveria estar aposentada. Quando não conseguiu mais trabalhar, continuou morando na casa de seus ex-patrões, como agregada.

Práxis Educativa, Ponta Grossa, v. 17, e2219374, p. 1-18, 2022

Disponível em: < https:// revistas2.uepg.br/index.php/praxiseducativa $>$. 
Mulheres negras em movimento: criações individuais e coletivas por vidas com dignidade e direitos

É importante reforçar que, para Maria do Carmo, o trabalho na esfera do doméstico foi ininterrupto, associado à servidão. Como não poderia deixar de ser, essa condição engrossa as fileiras do analfabetismo, da pobreza, da desqualificação profissional, da solidão e do isolamento social. A forma como Maria do Carmo demonstrou perceber a vida revela o peso da ideologia dos dominadores sobre os oprimidos, que mantém a maioria da população negra brasileira sem consciência dos efeitos da desigualdade ${ }^{3}$ e da exclusão.

Elementos da vida de Maria do Carmo levam à compreensão de uma das sagas da sociedade brasileira: o trabalho doméstico, embora muito digno, no imaginário social e pelas condições que é desenvolvido, é associado à escravidão e/ou à servidão. Essa vivência resulta em uma violência que aproxima a um estereótipo de raça, gênero e classe social - a existência das mulheres negras associada ao trabalho doméstico. Para Luciana de Oliveira Dias e Lyzyê Inácio Almeida (2021, p. 10), essa situação mantém-se mesmo quando é incorporada a ampliação dos direitos das trabalhadoras domésticas " [...] como na legislação trabalhista atual, na Lei Complementar no 150, anteriormente conhecida como a PEC das Domésticas, ainda se verifica a precarização desse tipo de emprego e a dificuldade da garantia de direitos pelo legislativo e pelos contratantes".

Considerando a necessidade de compreensão da realidade das mulheres negras, destaco alguns questionamentos:

- Quem são essas mulheres negras que historicamente compõem a vida cotidiana como figura anônima, salvo raríssimas exceções, carregando os fardos da opressão de gênero, raça e classe?

- Quais os condicionantes sociais, culturais e econômicos da vida das mulheres negras? Quais são as estratégias para garantir criatividades e se manterem determinadas na luta pela vida com qualidade?

- Quem são essas mulheres negras que se organizam e nos últimos anos despontam como setor politicamente emergente na sociedade brasileira? Quais são as contínuas demandas afirmadas, em âmbito nacional?

Mesmo que sem respostas finais, essas questões têm sido atualmente objetos de reflexões teórico-políticas nos meios acadêmicos e dos movimentos sociais, na busca de denunciar profundas exclusões e desigualdades e credenciar novos referenciais de análise que ampliem o leque de compreensão da realidade sob a perspectiva da construção positiva da identidade de gênero, raça e classe social.

O racismo está vivo, após 133 anos da abolição dos negros que foram escravizados por quase quatro séculos, mesmo com incessantes vozes chamando por justiça racial e liberdade. Devese considerar que o Brasil foi o último país nas Américas a abolir a escravidão e que a abolição de 1888 foi incompleta. Houve sim a libertação, mas às mulheres e aos homens ex-escravas/os não foi possibilitado o acesso à moradia, à terra, ao trabalho, à educação ou a qualquer condição que garantisse vida com qualidade e dignidade. Isso promoveu a perpetuação da desigualdade social e violência, até a atualidade.

Tanto no Brasil como na América Latina é forte a ideia de subdivisão das raças. Diferenças são transformadas em desigualdade, construindo a superioridade europeia (dos brancos) sobre os demais agrupamentos sociais. Em estudo da Comisión Económica para América Latina y el Caribe - Cepal (2020, p. 18), é reafirmado que "[...] se espalhou a ideia de que a espécie humana se subdividia em raças relacionadas a diferentes continentes e caracterizadas por características físicas

\footnotetext{
3 Alexandre de Freitas Barbosa (2011), no texto Cenários do desenvolvimento do Brasil, ao considerar a evolução histórica, econômica e social, afirma que a palavra-chave para o Brasil é a "desigualdade".
}

Práxis Educativa, Ponta Grossa, v. 17, e2219374, p. 1-18, 2022 Disponível em: < https://revistas2.uepg.br/index.php/praxiseducativa $>$. 
particulares - como a cor da pele, a textura do cabelo ou o formato do nariz e do crânio, entre outras".

Existe uma indissociabilidade entre classe social, gênero e raça, vidas negras são subjugadas e ceifadas, em nome dos privilégios e caprichos de uma minoria branca que se faz valer pela exploração e pela violência. Nesse contexto, é importante analisarmos que mulheres e homens vivem condições de extrema desigualdade. Francineide S. Palmeira e Florentina S. Souza (2008, p. 3) argumentam que os estereótipos de gênero e as ideias preconcebidas conformam o que seria apropriado para os indivíduos a depender do sexo submetido pelos papéis sociais. Nilton S. Formiga (2007, p. 384) complementa o raciocínio de Palmeira e Souza (2008) afirmando que, para a sociedade machista, cabe a mulher "[...] ser mãe e responsável a fim de prover o afeto na família, cuidar dos filhos, do esposo, etc.; define-se uma identidade em termos de sua dependência ou codependência, fragilidade e sensibilidade".

Outro aspecto bastante importante e pouco tratado socialmente está ligado ao resultado de discriminações e segregações desenvolvidas a partir da marginalização de grupos sociais cujas identidades são associadas à sexualidade, como a população LGBT, os profissionais do sexo e as pessoas que convivem com infecções sexualmente transmissíveis, entre outros. Nesse campo, é gerada a LGBTfobia que atua, de maneira geral, contra a dignidade da pessoa humana e a liberdade, desrespeitando os seus direitos a partir de ações violentas - físicas, verbais, morais ou psicológicas. Caio B. Pedra (2018, p. 10) questiona sobre quais não representam uma perda e quais “[...] não são passíveis de luto. Com isso se classifica quais são as vidas 'perdidas'. A morte (em casos de violência) é esperada como natural, isso para manutenção da normalidade, a favor da vida da maioria".

Racismo, sexismo e LGBTfobia são persistentes formas de violência. Marilena Chauí (2012, p. 155), no artigo Democracia e sociedade autoritária, argumenta que há, no Brasil, um mito da não-violência, isto é, “[...] a imagem de um povo generoso, alegre, sensual, solidário que desconhece o racismo, o machismo e a homofobia, que respeita as diferenças étnicas, religiosas e políticas, não discrimina as pessoas por sua classe social, etnia, religião ou escolha sexual etc.”. O que Chauí (2012) chama de mito da não violência, apresentado pela autoimagem de um povo ordeiro, pacífico, alegre, cordial e mestiço, é similar ao mito da democracia racial que cultiva a crença de que o Brasil é um paraíso racial, onde não há conflito e as relações sociais desenvolvem-se em harmonia racial e étnica, com forte expressão de um povo mestiço. Os mitos da não violência e da democracia racial levam à negação de direitos e reforça as exclusões sociais impostas aos seres humanos, pela não consideração da posição de cada um e da diversidade, levando à vivência do racismo, do sexismo e da LGBTfobia, para destacar apenas algumas formas.

Os percalços são muitos, mas, mesmo que com morosidades, tem sido nos últimos tempos abordadas as questões relacionadas ao racismo, ao sexismo e à LBGTfobia de maneira individual ou conjunta na vivência da sociedade ou institucionalmente (por meio de leis, normatizações, trabalhos educativos etc.).

\section{Mulheres negras no período contemporâneo: 33 anos de organização nacional e internacional}

A luta pela igualdade, direitos e justiça vêm de longe, desde a exploração dos povos indígenas e da escravização da população negra. Destaco algumas formas importantes de organização nacional pós-abolição até os dias atuais. No período de 1930 a 1970, a existência da Frente Negra Brasileira (FNB), nos anos de 1930/1940, e do Teatro Experimental do Negro (TEM), nos anos de 1950/1970. No período contemporâneo, do Movimento Negro Unificado

Práxis Educativa, Ponta Grossa, v. 17, e2219374, p. 1-18, 2022

Disponível em: < https:// revistas2.uepg.br/index.php/praxiseducativa $>$. 
(MNU), criado em 1978; da Coordenação de Entidades Negras (CONEN); da Organização e Negros pela Igualdade (Unegro); da Coalizão de Negros por Direitos, das Organizações de Mulheres Negras (Articulação Nacional de Mulheres Negras - ANMN; Coordenação Nacional de Mulheres Negras - CNMN; e Fórum Nacional de Mulheres Negras - FNMN); da juventude negra (Fórum Nacional de Juventude Negra); da Associação Brasileira de Pesquisadores Negros (ABPN); da Federação Nacional de Trabalhadoras Domésticas (Fenatrad), entre tantas outras.

O ano de 1988 foi emblemático em função da realização do I Encontro Nacional de Mulheres Negras (ENMN), na cidade de Valença, Rio de Janeiro, que impulsionou a construção de uma organização com fisionomia própria e caráter nacional. Esse processo foi possível pelos aprendizados a partir da resistência ancestral (RIBEIRO, 1995). O I ENMN possibilitou debater temáticas importantes, muitas delas sem consensos, como: legalização do aborto, sexualidade, relação com partidos políticos, religiosidade, entre outras.

Nos anos posteriores, outros encontros, seminários e eventos nacionais de mulheres negras ocorreram. Muitos grupos autônomos surgiram: Geledés Instituto da Mulher Negra, em São Paulo; Crioula Organização de Mulheres Negras, no Rio de Janeiro; Maria Mulher, no Rio Grande do Sul; Instituto da Mulher Negra (Inegra), no Ceará; Odara Instituto da Mulher Negra, na Bahia, entre tantos outros.

A organização de mulheres negras, expressão do Feminismo Negro brasileiro, apresenta uma grande singularidade, na sua própria estrutura e na relação com o Movimento Negro e o Movimento Feminista, como disputa de tendências, de poder, por acesso a recursos, por visibilidade. Segundo Cristiano S. Rodrigues e Marco Aurélio M. Prado (2010, p. 451), questões como o confronto entre as estruturas das Organizações Não Governamentais (ONGs) versus o modelo de movimento social de base são presentes na organização de mulheres negras como combinações entre eles "[...] e a questão do ambíguo impacto da institucionalização do Movimento de Mulheres Negras, sua adoção pelo Estado e por organismos internacionais de regulação”.

Paralelamente à organização específica, as mulheres negras participaram, em 1991, do I Encontro Nacional de Entidades Negras (Enen). Por tratar-se de um primeiro encontro dessa natureza, muitos foram os ineditismos e os debates sobre a atuação conjunta dos grupos e das entidades, a organização específica de mulheres negras, as questões nacionais pós abertura política (fim da ditadura militar), a violência racial, a relação com partidos políticos, entre outros.

Uma das principais ações contemporâneas em âmbito nacional foi a Marcha Zumbi dos Palmares contra o Racismo, pela Cidadania e pela Vida, realizada, em 20 de novembro de 1995, em Brasília. A Marcha foi liderada pelo Movimento Negro e pela organização de mulheres negras em parceria com outros setores do movimento social. Ao final, em um ato oficial, foi entregue ao Presidente da República na época - Fernando Henrique Cardoso (FHC) - o Programa de Superação do Racismo e da Desigualdade Racial, com reivindicações visando à inclusão da população negra nas políticas públicas - inserção no mercado de trabalho, educação, cultura e comunicação, saúde, combate à violência, e terra (MARCHA..., 1996). Embora esse documento tenha 26 anos, ele é bastante atual, considerando a permanência do quadro de exclusão social da população negra.

Em continuidade, em 2005, realizou-se a II Marcha Zumbi dos Palmares contra o Racismo, pela Cidadania e pela Vida, em Brasília. Conhecida como "Marcha Zumbi + 10", o evento teve duas versões: a mobilização do dia 16 de novembro de 2005, que enfocou a desigualdade socioeconômica e o baixo orçamento público destinado à população negra; e a manifestação do dia 22 de novembro de 2005, que enfatizou a anistia a João Cândido, o Almirante Negro, a exclusão social e a necessidade de combate à violência e ao genocídio da população negra (sobretudo dos jovens). Em comum, essas mobilizações tiveram o intuito de apresentar reflexões, críticas e 
proposições ao Presidente Luiz Inácio Lula da Silva, demandando a aceleração de medidas para o enfrentamento ao racismo.

Foi intensificada a participação internacional das mulheres negras brasileiras, como no I Encontro de Mulheres Negras Latinas e Caribenhas, em Santo Domingos/República Dominicana, em 1992, quando foi debatido o machismo, o racismo e as formas de combatê-los. Nesse momento, foi escolhida a data de 25 de julho como o Dia da Mulher Negra Latino-americana e Caribenha (reconhecido pela Organização das Nações Unidas - ONU), e foi criada, também, a Rede de Mulheres Latino-americanas, Caribenhas e Africanas, que permanece organizada até hoje (RIBEIRO, 2019).

Houve uma ampla participação das mulheres negras no ciclo de conferências convocadas pela ONU nos anos de 1990 a 2000, destacando-se a IV Conferência Mundial de Mulheres (China/Beijing, 1995) e a III Conferência Mundial contra o Racismo, a Discriminação Racial, a Xenofobia e as Intolerâncias Correlatas (África do Sul/Durban, 2001). Em continuidade a esses processos, as ativistas e as instituições têm participado do calendário global da Década Internacional dos Afrodescendentes, que desenvolve a temática: "Afrodescendentes: Reconhecimento, Justiça e Desenvolvimento (2015-2024)", estabelecida pela ONU (Resolução 68/2374), de 19 de dezembro de 2013. O Programa de Atividades apresenta a perspectiva de reforçar a cooperação nacional, regional e internacional em relação à garantia dos direitos econômicos, sociais, culturais, civis e políticos de pessoas de afrodescendentes, bem como a participação plena e igualitária em todos os aspectos da sociedade. Os Planos de Ação de Beijing, de Durban e da Década Internacional dos Afrodescendentes incorporam indicações para o urgente desenvolvimento de políticas públicas voltadas às mulheres negras.

Voltando ao âmbito nacional, no governo da Presidenta Dilma Rousseff, foi aprovada a Lei $\mathrm{N}^{\circ}$ 12.987, de 2 de junho de 2014, instituindo a data de 25 de julho como o Dia Nacional de Tereza de Benguela ${ }^{5}$ e da Mulher Negra (BRASIL, 2014), com o objetivo de fortalecer as organizações, reforçar seus laços e trazer maior visibilidade para a luta. Ressalto o envolvimento das mulheres negras nos processos de construção das políticas públicas nacionais, desenvolvidas pela Secretaria Especial de Políticas para Mulheres (SPM) e da Secretaria Especial de Políticas de Promoção da Igualdade Racial (Seppir), criadas na gestão do Governo Federal do Presidente Luiz Inácio Lula da Silva, em 2003. Esses órgãos promoveram, também, a participação social a partir da relação com a sociedade civil em diversos processos, como Conselhos Consultivos, Conferências Nacionais Temáticas (precedidas de eventos locais), Câmaras Técnicas, entre outras. Devemos considerar que a vivência entre Estado e sociedade civil não é um eterno "mar de rosas", mas a ação surtiu efeitos quanto à institucionalização das políticas públicas de gênero e raça (RIBEIRO, 2014).

Em 2015, foi realizada a Marcha Nacional das Mulheres Negras contra o Racismo, a Violência e pelo Bem Viver com objetivo de denunciar como a sociedade brasileira e o Estado excluem, violam e negligenciam os corpos negros, em especial os das mulheres negras. Aponta-se para um projeto de nação diferenciado do que vivemos, valorizando as múltiplas formas de resistência e as reivindicações pela vida plena - saúde, educação, arte, lazer, moradia.

\footnotetext{
${ }^{4}$ Disponível em: https://decada-afro-onu.org/N1362881_pt-br.pdf. Acesso em: 8 nov. 2021.

5 Conhecida também como Rainha Teresa, essa mulher negra marcou a história do Brasil. Grande estrategista e dirigente política à frente do Quilombo de Quariterê, no território que hoje corresponde ao Vale do Guaporé, Mato Grosso. Rainha Tereza estabeleceu uma forma de governar que funcionava à semelhança de um parlamento, com deputados, um conselheiro, reuniões e uma sede, como atestam documentos da época. O Quilombo existiu de 1730 a 1795, e a liderança de Benguela vigorou até 1770, quando foi presa e morta pelo Estado. Disponível em: http://www.esquerdadiario.com.br/25-de-julho-Dia-Nacional-de-Tereza-de-Benguela-a-lider-do-Quilombo-deQuaritere. Acesso em: 19 jul. 2021.
}

Práxis Educativa, Ponta Grossa, v. 17, e2219374, p. 1-18, 2022 Disponível em: < https://revistas2.uepg.br/index.php/praxiseducativa $>$. 
Nubia Regina Moreira e Thaís Teixeira Cardoso (2020, p. 131) alegam que as ativistas negras marcharam " [...] para apresentar um projeto político de ampliação da democracia brasileira e propor um novo pacto civilizatório. [...]. As demandas do feminismo negro são identificadas na atuação e luta contra as opressões de raça, classe e gênero que fazem parte do cotidiano das mulheres negras". A Marcha Nacional de Mulheres Negras é considerada como ação de enfrentamento e de manifestação política contundente. Houve uma perspectiva de negociação das reivindicações com o Estado brasileiro, visto que foi realizada audiência com a Presidenta Dilma Rousseff, momento em que as mulheres dos movimentos entregaram um manifesto com as suas demandas. Foi veiculada a Carta da Marcha Nacional das Mulheres Negras [MCMC] contra o Racismo e a Violência e pelo Bem Viver com o seguinte enunciado: "[...] marchamos pelo direito à vida, pelo direito à humanidade, pelo direito a ter direitos e pelo reconhecimento e valorização das diferenças. Marchamos por justiça, equidade, solidariedade e bem-estar que são valores inegociáveis, Viver" (CARTA DA MNMN, 2015).

Essa carta possui um rol de reinvindicações baseadas nos eixos: direito à vida e à liberdade; promoção da igualdade racial; direito ao trabalho, ao emprego e à proteção das mulheres negras em todas as atividades; direito à terra, ao território e à moradia/direito à cidade; justiça ambiental, defesa dos bens comuns e a não-mercantilização da vida; direito à seguridade social (saúde, assistência social e previdência social); direito à educação, direito à justiça; direito à cultura, à informação e à comunicação; e segurança pública. A coordenação da marcha considera que urge a execução de políticas capazes de não apenas melhorar as condições de vida de homens negros e de mulheres negras, mas eliminar a vulnerabilidade que põe em perigo a vida dessa população.

Três anos depois da Marcha Nacional das Mulheres Negras, em 2018, em Goiânia, Goiás, ocorreu o Encontro Nacional de Mulheres Negras 30 Anos: contra o Racismo e a Violência e pelo Bem Viver - Mulheres Negras Movem o Brasil. Cerca de mil ativistas do movimento de mulheres negras, participantes dos processos organizativos nos estados e no Distrito Federal, se fizeram presentes nesse momento que rememorou os 30 anos do I ENMN. O evento foi marcado por muitas atividades, destacando como pauta: combate ao racismo e ao sexismo; direitos sociais, como educação saúde, moradia, cultura; direito à terra e a territórios; intolerância religiosa; feminismo negro e violência contra a mulher.

Esse período mais recente da organização de mulheres negras ainda está sendo registrado e analisado, pois, embora haja um ativismo positivo, há um choque com a conjuntura política, econômica e social, situação de crise que se arrasta há alguns anos. Alguns elementos atuais dessa crise são: o Golpe Político de 2016, que resultou no impeachment da Presidenta Dilma Rousseff; a eleição de 2018 com a vitória nas urnas de Jair Bolsonaro, um presidente de extrema direita que tem promovido o desmonte das políticas públicas, desmantelando direitos sociais duramente conquistados pela classe trabalhadora; o desrespeito aos movimentos sociais; a pandemia da Covid19, que, por falta de uma política sanitária preventiva efetiva, incide negativamente na vida dos setores que já se encontravam em situação de vulnerabilidade (como a parcela mais pobre da população, os negros, as trabalhadoras domésticas, os idosos, entre outros). As desigualdades históricas e o atual momento de crise econômica, social, política, cultural e sanitária tornam os processos organizativos complexos, mas as organizações de mulheres negras estão firmes e rompem barreiras. Assim, as ações estão em curso - em âmbitos local, regional, nacional e internacional.

Convém mencionar que, embora vários dispositivos sejam usados para fazer perpetuar a existência de uma supremacia branca, masculina e heterossexual, fazendo com que as mulheres negras sejam atingidas pelas mais variadas formas de subalternização, houve sempre enfrentamento

Práxis Educativa, Ponta Grossa, v. 17, e2219374, p. 1-18, 2022

Disponível em: < https:// revistas2.uepg.br/index.php/praxiseducativa $>$. 
e resistência das negras frente aos desmandos de uma sociedade erigida pela lógica racista, patriarcal e permeada por uma desigualdade social profunda.

\section{Mulheres negras: a criatividade a serviço da construção acadêmica do conhecimento}

Nesta seção, irei abordar dois pontos fundamentais: a produção acadêmica coletiva com perspectiva feminista e antirracista e a Universidade da Integração Internacional da Lusofonia Afro-Brasileira (Unilab) como um importante passo para a Educação Superior e produção acadêmica afro-brasileira, africana e diaspórica.

\section{Produção acadêmica coletiva com perspectiva feminista e antirracista}

A produção nas universidades públicas sobre gênero e raça/etnia com perspectiva feminista negra e antirracista tem sido crescente, comumente com o desenvolvimento de grupos de estudos, pesquisa e extensão universitária, por iniciativas das/os docentes. Na maioria das vezes, essa produção não é viabilizada a partir de decisões institucionais das Reitorias e dos Conselhos Deliberativos. Também tem sido visível o número de docentes atuando de forma intercruzada entre o exercício acadêmico e o ativismo nos movimentos sociais (em especial Feminista e o Negro).

Kabengele Munanga (2005) valoriza o papel da ação educativa na qualidade de instrumento construtor do pensar e fazer críticos e adverte que as leis não são capazes de erradicar as atitudes preconceituosas, discriminatórias e excludentes impregnadas nas mentes e nos comportamentos. No entanto, "[...] cremos que a educação é capaz de oferecer tanto aos jovens como aos adultos, a possibilidade de questionar e desconstruir os mitos de superioridade e inferioridade entre grupos humanos que foram introjetados neles pela cultura racista na qual foram socializados" (MUNANGA, 2005, p. 17).

Quanto ao conhecimento acadêmico sobre o movimento de mulheres, Ângela Figueiredo (2018) enfatiza o interesse crescente de pesquisas por meio da elaboração de teses, dissertações, monografias e artigos em publicações nacionais e internacionais e, também, com divulgação pelas redes virtuais fazendo circular ideias e reflexões. Esse " [...] crescente interesse na articulação política das mulheres, através de organizações políticas ou não, está relacionado ao protagonismo das mulheres negras nos mais diferentes aspectos da vida social" (FIGUEIREDO, 2018, p. 1090).

Anteriormente à elaboração de Figueiredo (2018), podemos encontrar formulações de Ana Alice A. Costa e Cecília Maria B. Sardenberg (1994), que tratam do interesse sobre estudos e pesquisas sobre a mulher:

[...] em 1979 um passo importante no incentivo a produção científica nessa área será dado com a criação do Grupo de Trabalho sobre a Mulher e Força de Trabalho na ANPOCS [Associação Nacional de Pós-Graduação e Pesquisa em Ciências Sociais] e posteriormente, em 1980 na mesma Associação, com a criação do GT Mulher e Política. No mesmo ano será criado o primeiro núcleo de estudos em uma universidade brasileira, o Núcleo de Estudos da Mulher - NEM -, da Pontifícia Universidade Católica do Rio de Janeiro". (COSTA; SARDENBERG, 1994, p. 390).

As pesquisas voltadas às mulheres, feitas por Figueiredo (2018) e Costa e Sardenberg (1994) abriram caminhos para os estudos sobre diversidade. Nesse processo, embora muitos anos depois, mais especificamente no final dos anos de 1980, desenvolveram-se os estudos sobre mulheres negras aprofundando referenciais sobre questões étnico-raciais. Os estudos sobre as temáticas LGBTQIA+ tem seu desenvolvimento mais crescente a partir dos anos 2000.

Práxis Educativa, Ponta Grossa, v. 17, e2219374, p. 1-18, 2022

Disponível em: < https:// revistas2.uepg.br/index.php/praxiseducativa $>$. 
Dialogando com o item anterior (Mulheres negras no período contemporâneo: 33 anos de organização nacional e internacional), verifica-se que as próprias mulheres negras têm conquistado espaços acadêmicos e, com sua produção, avançam para transformar em reconhecimento o que antes era invisibilidade. Estudos das mulheres negras e sobre elas têm sido ampliados, isto é, as próprias têm atuado para serem sujeitas de sua própria história " [...] ainda de forma incipiente, têm sido tomadas como objeto de estudo dentro da academia brasileira, justamente pelo lugar de visibilidade que conseguiram construir a partir de sua militância e atuação política" (RODRIGUES; PRADO, 2010, p. 454).

Nas instituições públicas, nos campos de ensino, pesquisa e extensão universitárias, são agregadas/os pesquisadoras/es feministas de diferentes departamentos e de organizações nacionais e internacionais de maneira interdisciplinar. Os programas e os grupos têm contribuído para a formação de docentes e discentes, de pessoas vinculadas à gestão pública e privada e a movimentos sociais. A seguir, veremos alguns exemplos.

$\mathrm{Na}$ Universidade Federal da Bahia (UFBA), por iniciativa do Núcleo de Estudos Interdisciplinares sobre a Mulher (Neim), que existe desde 1983, foi criado, em 2006, o Programa de Pós-Graduação em Estudos Interdisciplinares sobre Mulheres, Gênero e Feminismo. Na atualidade, o Neim é coordenado por uma mulher negra acadêmica e ativista política ${ }^{6}$.

A Universidade Federal de Santa Catarina (UFSC), por meio do Instituto de Estudos de Gênero (IEG), articula redes de pesquisa e abriga seis frentes de atuação, vários laboratórios e núcleos voltados aos estudos de gênero, feminismos, sexualidades, diversidades e interseccionalidades. O IEG realiza o Seminário Internacional Faz̧endo Gênero, o qual avança para a $13^{a}$ edição. A $12^{a}$ edição foi realizada em julho de 2021, com o tema "Lugares de fala - direitos, diversidades, afetos" " ${ }^{7}$. No campo editorial, a UFSC publica a Revista Estudos Feministas (REF) ${ }^{8}$, um periódico quadrimestral do Centro de Filosofia e Ciências Humanas (CFCH). A REF foi criada em 1992, na Universidade Federal do Rio de Janeiro (UFRJ), e, em 1999, passou a ser editada pela UFSC com o objetivo de disseminar a produção de conhecimento na área de gênero, feminismo e suas interlocuções em âmbito nacional e internacional. Foram publicados pela REF três dossiês com a temática de gênero e raça, focando as mulheres negras, sendo estes: Mulheres Negras (coordenado por Matilde Ribeiro, com a contribuição de Mary Garcia Castro e Maria Luiza Heirlbon, em 1995); III Conferência Mundial contra o Racismo (coordenado por Luiza Bairros, em 2002); e 120 anos da Abolição, um processo inacabado (coordenado por Matilde Ribeiro e Flávia Piovesan, em 2008).

Estudos sobre questões étnico-raciais, destacando as populações negra e indígena e as mulheres são desenvolvidas pelos Núcleos de Estudos Afro-brasileiro e Indígena (Neabis), atualmente existentes na maioria das universidades públicas em função dos esforços para a aplicação da Lei $\mathrm{N}^{\circ}$ 10.639, de 9 de janeiro de 2003, e da Lei $\mathrm{N}^{\circ}$ 11.645, de 10 de março de 2008, que obrigam, respectivamente, o ensino da história afro-brasileira/africana e da cultura indígena (BRASIL, 2003, 2008).

Outro importante canal para estudos e debates sobre raça, racismo, políticas de igualdade racial no Brasil, na África e na Diáspora é a Associação Brasileira de Pesquisadores Negros (ABPN). Fundada em 2000, a ABPN congrega e fortalece pesquisadoras/es negras e negros nacionais e estrangeiras/os que trabalham com a perspectiva de enfrentamento ao racismo. São realizados

\footnotetext{
6 Sobre o Programa, ver https://www.ufba.br/estrutura/outros_orgaos/n\%C3\%BAcleo-de-estudosinterdisciplinares-sobre-mulher-neim. Acesso em: 28 jul. 2021.

7 Ver sobre o Seminário em http://fazendogenero.ufsc.br/12/. Acesso em: 15 jul. 2021.

${ }^{8}$ Disponível em: https://periodicos.ufsc.br/index.php/ref/login/signIn. Acesso em: 21 jul. 2021.
}

Práxis Educativa, Ponta Grossa, v. 17, e2219374, p. 1-18, 2022

Disponível em: < https://revistas2.uepg.br/index.php/praxiseducativa $>$. 
Congressos Regionais e Congresso Nacional. Com o objetivo de dar visibilidade ao trabalho realizado, é publicada a Revista da $A B P N$, periódico trimestral eletrônico?.

As informações anteriores são apenas alguns exemplos, considerando o vasto universo da Educação Superior no Brasil. Considerando a densidade das atuações, destaco que existem experiências exitosas que necessitam ser conhecidas e divulgadas.

\section{Unilab: importante passo para a Educação Superior e produção acadêmica afro-brasileira, africana e diaspórica}

A Universidade da Integração Internacional da Lusofonia Afro-Brasileira (Unilab) tem 11 anos de existência e é sediada em dois Estados: Ceará (nos municípios de Redenção e Acarape, com os campi de Liberdade, inaugurado em 2010, e, posteriormente, Palmares e Auroras) e Bahia (São Francisco do Conde, com o campus Malês, inaugurado em 2014). ${ }^{10}$

Com as finalidades de desenvolvimento de ensino, pesquisa e extensão universitária, a Unilab desenvolve-se a partir da interiorização e internacionalização, tendo com predominância a presença de estudantes do interior da Bahia e do Ceará e dos países africanos de língua oficial portuguesa. Têm por missão institucional específica formar recursos humanos para contribuir com a integração entre o Brasil e os demais países membros da Comunidade dos Países de Língua Portuguesa (CPLP), especialmente os Países Africanos de Língua Oficial Portuguesa (Palop) Angola, Cabo Verde, Guiné Bissau, Moçambique e São Tomé e Príncipe, fortalecendo a cooperação Sul-Sul. Visa, também, o tratamento de questões relativas à diversidade étnico-racial, cultural, religiosa, de gênero e de orientação sexual com o intuito de contribuir para a superação das desigualdades ${ }^{11}$.

Dada a importância da integração internacional, em julho de 2012, foi criada a Rede de Instituições Públicas de Educação Superior (Ripes), coordenada pela Pró-Reitoria de Relações Institucionais e Internacionais (Prointer) com o apoio da Agência Brasileira de Cooperação (ABC) do Ministério das Relações Exteriores (MRE). A Ripes tem como principal objetivo criar e fortalecer a comunicação entre as instituições públicas de Ensino Superior da CPLP, respeitando a soberania dos países e das instituições parceiras e promovendo ações e intervenções de apoio técnico, administrativo e acadêmico.

Outra forma de articulação internacional é a Rede Internacional de Mulheres Africanas da Unilab (Rima), também chamada de Rede Ópébamu (palavra que significa, na língua São Tomense, solidariedade para caminhar juntas), criada no "Dia da Mulher Africana", em 31 de julho de 2017, com o intuito de construir firme liderança com viés acadêmico, promover a sororidade e a transformação das mentalidades e dos comportamentos históricos e culturais e trazer para o debate a realidade das mulheres africanas no contexto africano e da diáspora. A Rima desenvolve, em parceria com a Prointer, por meio do Programa de Extensão Vozes D’África, a Conferência de Mulheres Africanas da Unilab, que, na segunda edição, em julho de 2021, teve o tema "Mulheres

\footnotetext{
${ }_{9}^{9}$ Sobre a Revista, ver https://www.abpnrevista.org.br/index.php/site/issue/view/40. Acesso em: 21 jul. 2021.

${ }^{10}$ No Ceará, o município de Redenção passou a ser a sede da Unilab pelo histórico de ter sido a primeira cidade a abolir a escravidão no país, em 1 de janeiro de 1883. Essa cidade localiza-se na região do Maciço de Baturité, a 63 km de Fortaleza (capital do Ceará). A cidade de São Francisco do Conde, na Bahia, a escolha deu-se, entre outros motivos, por ser um dos municípios com maior densidade de negros.

11 Resolução Complementar Consuni $N^{o}$ 3, de 4 de dezembro de 2020 - Estatuto da Unilab. Disponível em: https://unilab.edu.br/estatuto-da-unilab/. Acesso em: 30 jul. 2021.
}

Práxis Educativa, Ponta Grossa, v. 17, e2219374, p. 1-18, 2022 Disponível em: < https:// revistas2.uepg.br/index.php/praxiseducativa $>$. 
Mulheres negras em movimento: criações individuais e coletivas por vidas com dignidade e direitos

africanas e a produção do conhecimento endógeno na ciência: um olhar sobre a circulação de saberes em África" ${ }^{\prime 2}$.

No que diz respeito às atuações nas áreas dos direitos humanos, promoção de igualdade racial e gênero, existem o Núcleo de Políticas de Gênero e Sexualidades (NPGS) e o Serviço de Promoção da Igualdade Racial Kabengele Munanga (Sepir), vinculados à Pró-Reitoria de Políticas Afirmativas e Estudantis (Propae) e à Coordenação de Direitos Humanos (CDH). O NPGS está com atividades suspensas por tempo indeterminado, dependendo de negociações entre docentes e a direção da universidade para a sua retomada. Manteve seu funcionamento por seis anos com o objetivo de socialização de conhecimento e fortalecimento de parcerias acadêmicas, visando a promover ações para difundir o debate na área dos estudos de gênero, feminismos, sexualidades, enfrentamento à violência contra a mulher, à lesbo-homo-transfobia, a atitudes de preconceito e discriminação e o enfrentamento ao preconceito de origem, raça, sexo, cor, idade e quaisquer outras formas de discriminação ${ }^{13}$.

O Sepir desenvolve ações destinadas à promoção e à valorização da igualdade étnico-racial e à proteção dos direitos de indivíduos e grupos afetados por discriminação e preconceito, envolvendo a comunidade universitária, dentro e fora de seus campi (UNILAB, 2020). O Sepir também realiza, desde 2016, o projeto de extensão universitária Novembro Afro-Brasileiro, em alusão ao 20 de novembro - Dia da Consciência Negra e de Zumbi dos Palmares. Esse evento caminha para a sexta edição, que, para Arilson dos Santos Gomes (2020, p. 56), possibilita “[...] a formação para a educação das relações étnico-raciais de maneira potente e qualificada, tanto para dentro da instituição como para as comunidades circundantes".

Em junho de 2021, foi criado o Núcleo de Estudos Africanos, Afro-Brasileiros e Indígenas (Neaabi), o qual unificou as ações dos Campis Malês, na Bahia, e Liberdade, no Ceará, vinculado à Pró-Reitoria de Extensão, Arte e Cultura (Proex). O Neaabi visa o fortalecimento dos estudos africanos, afro-brasileiros e indígenas, visibilizando e disseminando a diversidade étnica e cultural, por meio da organização de projetos, da produção e da divulgação de materiais, da promoção de diálogo entre a comunidade acadêmica ${ }^{14}$.

O Curso Especialização Lato Sensu em Gênero, Diversidade e Direitos Humanos $(\mathrm{GDDH})$ aborda a promoção da equidade de gênero e do reconhecimento da diversidade de orientação afetivo-sexual e/ou identidade de gênero, ao sexismo, à misoginia e à LGBTfobia. O curso fomenta a educação permanente, aperfeiçoando conhecimentos, habilidades e atitudes, instrumentalizando para o tratamento das questões de gênero e suas interseccionalidades, notadamente no plano dos direitos humanos e práticas das políticas públicas ${ }^{15}$.

Em 2011, realizou-se o I Curso de Especialização em História e Cultura Africana e dos Afrodescendentes voltado à formação de Professores de Quilombos no Ceará, sob coordenação do Núcleo de Estudo das Africanidades Cearenses (Nace), da Faculdade de Educação da

\footnotetext{
12 Sobre a Conferência, acesse https://unilab.edu.br/2021/07/21/ii-conferencia-de-mulheres-africanas-na-unilabtraz-um-olhar-sobre-circulacao-de-saberes-em-africa/. Acesso em: 25 jul. 2021.

13 O Regimento Interno do Núcleo de Políticas de Gênero e Sexualidades - NPGS/Propae/Unilab pode ser encontrado em https://unilab.edu.br/2014/06/16/nucleo-de-politicas-de-genero-e-sexualidades-inaugura-sede-nospalmares/. Acesso em: 31 jul. 2021.

${ }^{14}$ Ver Resolução Complementar Consuni/Unilab No 7, de 17 de junho de 2021. Criação do Núcleo de Estudos Africanos, Afro-Brasileiros e Indígenas (NEAABI). Disponível em: https://unilab.edu.br/wpcontent/uploads/2021/06/Resolucao-Complementar-Consuni-Unilab-no-7-de-17-de-junho-de-2021.pdf. Acesso em: 31 jul. 2021.

15 Sobre o curso, ver https://unilab.edu.br/iead/genero-diversidade-e-direitos/. Acesso em: 31 jul. 2021.
}

Práxis Educativa, Ponta Grossa, v. 17, e2219374, p. 1-18, 2022

Disponível em: < https://revistas2.uepg.br/index.php/praxiseducativa $>$. 
Universidade Federal do Ceará (UFC), em parceria com a Unilab. As bases para esse curso e demais atividades são os estudos sobre Pretagogia (perspectiva teórico-metodológica de enraizamento da conexão com a afroancestralidade, afrocentralidade e a africanidade), destacando-se algumas produções: Pret@gogia: referencial teórico-metodológico para o ensino da história e cultura africana e dos afrodescendentes (PETIT; COSTA E SILVA, 2011); Pretagogia: construindo um referencial teórico-metodológico de base africana para formação de professoras/es (SILVA, 2019); e A formação docente afrocentrada da Unilab: o saber docente ancestral no ensino de didática nos países da integração (MEIJER, 2019).

Um dos meios de circulação de produção das/os docentes e das/os discentes são as revistas eletrônicas, as quais contemplam questões sociais, econômicas e culturais e, também, a diversidade étnico-racial, religiosa, de gênero e de orientação sexual no Brasil, África e Diáspora, sendo estas: a Revista Njinga \& Sepé - Revista Internacional de Culturas, Linguas Africanas e Brasileiras; a Revista Batuko; a Ayé Revista de Antropologia; a Revista Interdisciplinar em Ciências Ambientais e Agrárias - Reicaa; a Revista Brasileira de Estudos da Homocultura - Rebeh; a Mandinga - Revista de Estudos Linguísticos; e a Capoeira Revista de Humanidades e Letras.

São vários os grupos de estudos, pesquisa e extensão universitária em diferentes áreas, os quais visam a contribuir para a democracia, a inclusão e a justiça social em âmbito nacional e internacional. Estes se desenvolvem em uma perspectiva interdisciplinar e anticolonial, envolvendo pesquisadores e estudantes, integrantes de organizações públicas e privadas, organizações não governamentais, movimentos sociais, universidades públicas federais e estaduais. Nesse sentido, na sequência, apresento algumas experiências.

O grupo Sobre o Corpo Feminino - Literaturas africanas e afro-brasileiras, vinculado ao Instituto de Linguagens e Literatura (ILL), desenvolve o projeto Julho das Pretas na Unilab - Encontro de Mulheres Afrolatino-americanas, Caribenhas e Africanas que está na quinta edição anual e celebra o 25 de julho - Dia Internacional da Mulher Afrolatino-americana, Caribenha e Africana e Dia Nacional Tereza Benguela e da Mulher Negra. Essa atividade desenvolve-se a partir de parcerias com a Rede de Mulheres do Ceará e a Rede de Mulheres Negras no Nordeste. Outro projeto é o Ciclo de estudos e debates sobre o corpo feminino, literaturas africanas e afro-brasileira. Nas duas experiências, enfatiza-se o compromisso com o estabelecimento de diálogos entre os "[...] campos do ensino interdisciplinar das literaturas africanas e afro-brasileiras, das artes e das ciências humanas, e o campo da pesquisa, base importante do Projeto Político Pedagógico da UNILAB” (COSTA et al. 2020, p. 16).

O Centro de Estudos Interdisciplinares Africanos e da Diáspora (Ceiáfrica), em parceria com o Laboratório de Estudos e Pesquisas em Afrobrasilidade, Gênero e Família (Nuafro), da Universidade Estadual do Ceará (Uece), desenvolve o projeto Mulberes Negras Resistem: processo formativo teórico-político, vinculado à área de Antropologia do Instituto de Humanidades. O Mulheres Negras Resistem caminha para a quinta edição anual, com o objetivo de fomentar o protagonismo feminino e negro, por meio da formação de quadros para a representação social e política. Para isso, há o alinhamento da perspectiva teórico-política com ênfase no feminismo negro. Vera Rodrigues (2020, p. 47) detalha que são ofertadas, a cada ano, 25 novas vagas, possibilitando as participantes a "[...] estudar, debater e criar projetos de intervenção social voltado para ações comunitárias ou projetos acadêmicos que visam o ingresso dessas mulheres na pós-graduação em universidades públicas".

O AMANDLA - Grupo de estudo, pesquisa e extensão sobre políticas públicas de gênero, étnico-raciais, desenvolvimento e territorialidade ${ }^{16}$ é coordenado por Matilde Ribeiro e Joana D’Arc Sousa Lima e vincula-se à área de Pedagogia do Instituto de Humanidades. Entre alguns trabalhos realizados,

${ }^{16}$ Informações sobre o grupo, ver http://dgp.cnpq.br/dgp/espelhogrupo/5576248465611642. Acesso em: 21 jul. 2021.

Práxis Educativa, Ponta Grossa, v. 17, e2219374, p. 1-18, 2022 Disponível em: < https:// revistas2.uepg.br/index.php/praxiseducativa $>$. 
destaco, desde o início de 2021, a Pesquisa sobre Políticas Públicas de Promoção Racial no Brasil (20102021), em continuidade ao estudo com a mesma temática, realizado por Matilde Ribeiro, abarcando o período de 1986 a 2010 (RIBEIRO, 2014). Outras ações estão em planejamento para 2022, como: o Festival Multidisciplinar Mandela Day, as atividades de capacitação visando o destaque para comunidades quilombolas, mulheres negras, entre outras.

Criado em 2016, o AZÂNIA, Grupo de Estudos e Pesquisas em Cultura, Gêneros, Sexualidades, Raça, Classe, Performances, Religião e Educação ${ }^{17}$ realizou, entre outras atividades, a pesquisa As concepcões de gênero, sexualidade e religião na prática docente em parceria com a Universidade Federal Fluminense (UFF) e a Pontifícia Universidade Católica de São Paulo (PUC-SP).

Desde 2014, o grupo de pesquisa FEMPOS (Pós-colonialidade, Feminismo e Epistemologias Antihegemônicas) aloca-se na área de Filosofia. Tem como objetivo trabalhar sobre as contribuições teóricas das correntes interseccionais e pós/decoloniais do feminismo e da Teoria Queer em uma perspectiva transnacional, privilegiando, de maneira particular, o eixo Sul-Sul. Dois volumes foram publicados a partir de traduções de textos de autores africanos sobre a dissidência sexual e de gênero em vários países africanos de ex-colonização britânica: Traduð̨indo a Africa Queer (REA; PARADIS; AMANCIO, 2018) e Traduæindo a África Queer II (REA; FONSECA; SILVA, 2020), pela editora Devires, de Salvador.

O grupo de pesquisa Centro Interdisciplinar de Estudos de Gênero - Dandara tem por objetivo

[...] dedicar-se aos estudos interdisciplinares das relações de gênero em interface com as relações étnico-raciais, no que tange a construção das subjetividades, das identidades, das memórias, das produções literárias, dos processos formativos, das práticas socioculturais e sociodiscursivas acerca das feminilidades e masculinidades, em uma perspectiva decolonial/pós-colonial e intercultural. (CASTRO, 2019, n.p.).

A Unilab, em sua trajetória, tem demonstrado um grande potencial e esforço por parte das/os docentes e das/os discentes na área de estudo, pesquisa e extensão universitária, em suas dimensões nacional e internacional. As redes, grupos, núcleos e serviços têm vida ativa, porém carecem de maior apoio estrutural e financeiro no que diz respeito à garantia de bolsistas, apoio a colaboradores e registros de experiências. Em especial, o NPGS necessita ser retomado, tendo em vista a importância da temática de gênero e sexualidade para o todo da universidade. Ainda, faz-se necessário o incremento das relações internacionais com o fortalecimento da cooperação institucional. São muitas as conquistas, mas os desafios são múltiplos: o cumprimento da missão de interiorização e internacionalização; a prática intensa da democratização da gestão; o atendimento às demandas de equidade entre os gêneros, étnico-raciais e LGBTQIA+ no cotidiano da universidade.

\section{Breves reflexões finais}

Neste apanhado sobre o processo organizativo das mulheres negras, foi possível apreender a determinação pela vida, com seus cotidianos díspares e a busca de um lugar ao sol. As mulheres negras, como a indicação do poema Cabeça Feita, apresentado no início deste artigo, vão trançando e traçando novos destinos. Grande inspiração para as reflexões, de maneira singular e ao mesmo tempo plural, foi a instigante história de Maria do Carmo Gerônimo. Como mais um ato de desagravo, as mulheres negras brasileiras - independentemente da profissão, da titulação e/ou da condição social - deveriam dizer Somos todas Maria do Carmo! Com isso, seria fortalecida e

${ }^{17}$ Sobre o grupo, ver https:/ / unilab.edu.br/2020/008/10/grupo-de-estudos-azania-promove-webinario-no-periodode-12-a-14/. Acesso em: 21 jul. 2021.

Práxis Educativa, Ponta Grossa, v. 17, e2219374, p. 1-18, 2022

Disponível em: < https:// revistas2.uepg.br/index.php/praxiseducativa $>$. 
visibilizada a construção de identidade coletiva positiva. Maria do Carmo, assim como a maioria das mulheres negras, não possuía (ou possuem) uma narrativa de defesa das adversidades e das crueldades moldadas pelas desigualdades, pelo racismo, pelo sexismo e pela LGBTfobia - daí a necessidade de os processos organizativos da população negra e das mulheres negras promoverem um levante político!

As organizações das mulheres negras sempre realizaram um levante político. Por meio de organização feminista específica, mantêm contínua relação com o Movimento Feminista e o Movimento Negro. Como produto dessa relação, Sueli Carneiro (2003) valoriza o resultado do enegrecimento do Movimento Feminista e da ampliação do protagonismo das mulheres negras no Movimento Negro (e movimento social, de maneira geral) e na sociedade, como um aspecto altamente positivo.

É notória a ampliação da atuação das mulheres negras no espaço público como sujeitos coletivos, afirmando a visão de que, para além de práticas e de pertencimentos (ser mulher negra), "[...] buscam também o reconhecimento da diferença (a especificidade desse pertencimento), articulando em sua construção identitária reivindicações do discurso democrático e de direitos de outros sujeitos sociais oprimidos" (RODRIGUES; PRADO, 2010, p. 453). As atuações sistemáticas das mulheres negras nas questões de classe social, gênero e raça/etnia contribuem para a estruturação de instituições acadêmicas, políticas e sociais para o fortalecimento do movimento social e vice-versa, com isso provocam repercussão das lutas para a sociedade.

O momento planetário é bastante difícil, as crises econômica, sanitária e humanitária tornam o dia a dia assustador. As ações e as discussões da organização das mulheres negras em conjunto aos demais movimentos sociais têm proporcionado analisar a conjuntura sobre o aprofundamento das desigualdades, do acirramento do racismo, da concentração de riquezas nas mãos de poucos, da persistência da fome e do feminicídio, do assassinato de jovens negros, da precarização do trabalho, da apropriação dos bens produzidos por todas e todos pelo capital internacional, entre outros.

São muitos os desafios e as necessidades de ajustes de rotas, valorizando efetivamente os grupos vulnerabilizados historicamente no cotidiano da vida, na política ou nas instituições acadêmicas. A organização das mulheres negras, como antena giratória, capta sentidos, comportamentos e energias para o novo. O ponto previsto para a chegada é sabido: a somatória das formas de atuação críticas e democráticas apontam para um horizonte em que as desigualdades acirradas pelo racismo, pelo sexismo e pela LGBTfobia sejam superadas. Sigamos!

\section{Referências}

BARBOSA, A. F. (org.). Cenários do desenvolvimento do Brasil 2020. Revista Análises e Propostas, São Paulo, v. 41, 2011. Disponível em: https://library.fes.de/pdffiles/bueros/brasilien/08121.pdf. Acesso em: 8 nov. 2021.

BRASIL. Lei No 10.639, de 9 de janeiro de 2003. Altera a Lei no 9.394, de 20 de dezembro de 1996, que estabelece as diretrizes e bases da educação nacional, para incluir no currículo oficial da Rede de Ensino a obrigatoriedade da temática "História e Cultura Afro-Brasileira", e dá outras providências. Diário Oficial da União: seção 1, Brasília, DF, n. 8, p. 1, 10 jan. 2003.

BRASIL. Lei $\mathrm{N}^{\circ}$ 11.645, de 10 março de 2008. Altera a Lei no 9.394, de 20 de dezembro de 1996, modificada pela Lei no 10.639, de 9 de janeiro de 2003, que estabelece as diretrizes e bases da educação nacional, para incluir no currículo oficial da rede de ensino a obrigatoriedade da temática

Práxis Educativa, Ponta Grossa, v. 17, e2219374, p. 1-18, 2022

Disponível em: < https://revistas2.uepg.br/index.php/praxiseducativa $>$. 
"História e Cultura Afro-Brasileira e Indígena. Diário Oficial da União: seção 1, Brasília, DF, n. 48, p. 1, 11 mar. 2008.

BRASIL. Lei $\mathbf{N}^{\circ}$ 12.987, de 2 de junho de 2014. Dispõe sobre a criação do Dia Nacional de Tereza de Benguela e da Mulher Negra. Brasília: Presidência da República, Casa Civil, Subchefia para Assuntos Jurídicos, [2014]. Disponível em: http://www.planalto.gov.br/ccivil_03/_ato20112014/2014/lei/112987.htm. Acesso: 26 abr. 2021.

CARNEIRO, S. Enegrecer o feminismo: a situação da mulher negra na América Latina a partir de uma perspectiva de gênero. Ashoka Empreendimentos Sociais. Rio de Janeiro: Takano e Cidadania Editora, 2003.

CARTA da Marcha Nacional de Mulheres Negras. Marcha contra o racismo, a violência e pelo bem viver. Documento Analítico e Declaração. Brasília, 2015. Disponível em: http:/ / fopir.org.br/wp-content/uploads/2017/01/Carta-das-Mulheres-Negras-2015.pdf. Acesso em: 8 nov. 2021.

CASTRO, M. D. Novo Centro Interdisciplinar de Estudos de Gênero (Cieg Dandara) terá evento de lançamento nesta quarta-feira (6). Unilab, 29 jan. 2019. Disponível em: https://unilab.edu.br/2019/01/29/novo-centro-interdisciplinar-de-estudos-de-genero-ciegdandara-tera-evento-de-lancamento-no-proximo-dia-6-2/. Acesso em: 31 jul. 2021.

CEPAL. Comisión Económica para América Latina y el Caribe/UNFPA - Fondo de Población de las Naciones Unidas. Afrodescendientes y la matriz de la desigualdad social en América Latina: retos para la inclusión. Documentos de Proyectos (LC/PUB.2020/14), Santiago, 2020.

CHAUÍ, M. Democracia e sociedade autoritária. Revista Comunicação \& Informação, Goiânia, v. 15, n. 2, p. 149-161, jul./dez. 2012.

COSTA, A. A. A.; SARDENBERG, C. M. B. Teoria e Práxis Feministas na Academia: os núcleos de estudos sobre a mulher nas universidades brasileiras. Revista Estudos Feministas, Rio de Janeiro, n. esp., p. 387-400, out. 1994. DOI: https://doi.org/10.1590/\%25x

COSTA, L. A. et al. Quando mulheres negras recriam o mundo das palavras: relato de experiência de alunas do projeto de extensão sobre o corpo feminino - literaturas africanas e afro-brasileira. Batuko: Revista Cadernos de Arte e Cultura da Unilab, Redenção, ano I, v. 4, p. 22-27, nov. 2020.

DIAS, L. O.; ALMEIDA, L. I. Eu empregada doméstica: heranças, resistências e enfrentamentos das trabalhadoras domésticas no Brasil. TESSITURAS - Revista de Antropologia e Arqueologia, Pelotas, v. 9, n. 1, p. 8-31, jan./jun. 2021. DOI: https://doi.org/10.15210/tes.v9i1.19297

FIGUEIREDO, A. Perspectivas e contribuições das organizações de mulheres negras e feministas negras contra o racismo e o sexismo na sociedade brasileira. Revista Direito e Práxis, Rio de Janeiro, v. 9, n. 2, p. 1080-1099, 2018. DOI: https://doi.org/10.1590/2179-8966/2018/33942

FORMIGA, N. S. Valores humanos e sexismo ambivalente. Revista do Departamento de Psicologia, Rio de Janeiro, v. 19, n. 2, p. 381-396, jul./dez. 2007. DOI: https://doi.org/10.1590/s0104-80232007000200009

GOMES, A. S. Ação e extensão: o Novembro Afro-Brasileiro e a promoção da igualdade racial. Batuko: Revista Cadernos de Arte e Cultura da Unilab, Redenção, ano I, v. 4, p. 51-56, nov. 2020.

LIMA, J. D. Conceição Evaristo: 'minha escrita é contaminada pela condição de mulher negra'. Nexo, 26 maio de 2017.2 Disponível em: 
https://www.nexojornal.com.br/entrevista/2017/05/26/Concei $\% C 3 \% A 7 \% C 3 \% A 3 o-E v a r i s t o-$ $\%$ E2 $\% 80 \% 98$ minha-escrita- $\%$ C3 $\%$ A 9 -contaminada-pela-condi $\% \mathrm{C} 3 \% \mathrm{~A} 7 \% \mathrm{C} 3 \%$ A3o-de-mulhernegra $\%$ E2\%80\%99. Acesso em: 20 jul. 2021.

MARCHA Zumbi dos Palmares contra o racismo, pela cidadania e a vida. Programa Nacional de Combate ao Racismo e a Desigualdade Racial. Brasília: Cultura Gráfica e Editora, 1996.

MEIJER, R. A. S. A formação docente afrocentrada da Unilab: o saber docente ancestral no ensino de didática nos países da integração. Revista Debates em Educação, Maceió, v. 11, n. 23, p. 598611, jan./abr. 2019. DOI: https://doi.org/10.28998/2175-6600.2019v11n23p598-611

MOREIRA, N. R.; CARDOSO, T. T. Mulheres negras em marcha contra o racismo, à violência e pelo bem viver: indícios para um currículo antirracista. Cadernos de Pesquisa, São Luís, v. 28, n. 4, p. 129-151, out./dez. 2020. DOI: https://doi.org/10.18764/2178-2229.v27n4p129-151

MUNANGA, K. Apresentação. In: MUNANGA, K. (org.). Superando o racismo na escola. 2. ed. rev. Brasília: MEC/SECAD, 2005. p. 15-20.

PALMEIRA, F. S.; SOUZA, F. S. Representações de gênero e afrodescendência na obra de Conceição Evaristo. In: ENCONTRO DE ESTUDOS MULTIDISCIPLINARES EM CULTURA - ENECULT, 4., 2008, Salvador. Anais eletrônicos [...]. Salvador: UFBA. Disponível em: http://www.cult.ufba.br/enecult2008/14440.pdf. Acesso em: 8 nov. 2021.

PEDRA, C. B. Direitos LGBT: A LGBTfobia estrutural na arena jurídica. 2018. Dissertação (Mestrado em Ciências do Estado) - Programa de Pós-Graduação da Faculdade de Direito e Ciências do Estado, Universidade Federal de Minas Gerais, Belo Horizonte, 2018.

PETIT, S. H.; SILVA, G. C. Pret@gogia: referencial teórico-metodológico para o ensino da História e Cultura Africana e dos Afrodescendentes. Fortaleza: UFC, 2011.

REA, C.; FONSECA, J. B. S. da; SILVA, A. C. B. B. Traduzindo a África Queer II. Salvador: Devires, 2020.

REA, C.; PARADIS, C. G.; AMANCIO, I. M. S. Traduzindo a África Queer. Salvador: Devires, 2018.

RIBEIRO, M. Mulheres Negras: uma trajetória de criatividade, determinação e organização. SANTANA, B. (org.). Vozes Emergentes de mulheres negras. Belo Horizonte: Mazza Edições, 2019. p. 234-272.

RIBEIRO, M. Políticas para Igualdade Racial no Brasil (1986/2010). Rio de Janeiro: Garamond, 2014.

RIBEIRO, M. Todas Negras: uma vida, muitas vidas. Revista Cuíra: Amazônia \& Cidadania. Belém: Unipop, 1996.

RIBEIRO, M. Mulheres Negras brasileiras, de Bertioga a Beijing (Dossiê Mulheres Negras). Revista Estudos Feministas, Rio de Janeiro, v. 3, n. 2, p. 446-457, 1995.

RODRIGUES, C. S.; PRADO, M. A. M. Movimento de mulheres negras: trajetória política, práticas mobilizatórias e articulações com o Estado brasileiro. Revista Psicologia \& Sociedade, Recife, v. 22, n. 3, p. 445-456, 2010. DOI: https://doi.org/10.1590/s0102-71822010000300005 
RODRIGES, V. Projeto Mulheres negras resistem: uma experiência de extensão, arte e cultura na Unilab. Batuko: Revista Cadernos de Arte e Cultura da Unilab, Redenção, ano I, v. 4, p. 46-50, nov. 2020.

SILVA, G. C. Pretagogia: construindo um referencial teórico-metodológico de base africana para formação de professores/as. Fortaleza: Editora Imprece, 2019.

UNILAB. Universidade da Integração Internacional da Lusofonia Afro-Brasileira. Relatório de gestão. Serviço de Promoção da Igualdade Racial Kabengele Munanga (Sepir). Redenção: Unilab, 2020.

WIKIPÉDIA. A enciclopédia livre. Maria do Carmo Gerônimo. Wikipédia, 2020. Disponível em: https://pt.wikipedia.org/wiki/Maria_do_Carmo_Ger\%C3\%B4nimo. Acesso em: 8 nov. 2021.

Recebido em 10/08/2021

Versão corrigida recebida em 04/11/2021

Aceito em 05/11/2021

Publicado online em 16/11/2021 